\title{
Surgical emphysema and \\ pneumomediastinum complicating dental extraction
}

\author{
A. Ali, ${ }^{1}$ D. R. Cunliffe, ${ }^{2}$ and S. R. Watt-Smith, ${ }^{3}$
}

\section{Subcutaneous and mediastinal emphysema is a rare complication of dental extraction and the use of air turbines has often been implicated. We describe a case which highlights a serious complication of the use of an air rotor for the removal of a right second mandibular molar.}

$\mathrm{P}$ neumomediastinum implies free air within the mediastinum, which is a relatively uncommon, usually benign, selflimiting condition of young men and parturient women and is frequently found without apparent precipitatory cause. Subcutaneous and mediastinal emphysema has been previously reported after dental and oral surgical procedures, but remains a rare complication of exodontia using compressed air equipment. ${ }^{1}$

\section{Case report:}

A 47-year-old male was referred to the accident and emergency department with a history of central chest pain, bilateral neck swelling and dysphagia. That morning he had had a lower right second molar surgically extracted under local anaethesia by a general dental practitioner, who described it as a difficult, protracted procedure.

On examination his pulse was $74 / \mathrm{min}$, blood pressure $127 / 70 \mathrm{~mm} \mathrm{Hg}$, respiratory rate $16 / \mathrm{min}$, temperature $36.3^{\circ} \mathrm{C}$, and maintaining oxygen saturation 100\%. Examination revealed a bilateral neck swelling and trachea in midline, with crepitus on palpation suggesting profound surgical emphysema. His posteroanterior neck radiograph

$1^{*}$ Senior House Officer, Oral and Maxillofacia Surgery Unit, John Radcliffe Hospital, Oxford OX3 9DU; ${ }^{2}$ Specialist Registrar, Oral and Maxillofacial Surgery Unit, John Radcliffe Hospital, Oxford OX3 9DU; ${ }^{3}$ Consultant, Oral and Maxillofacial Surgeon, Oral and Maxillofacial Surgery Unit, John Radcliffe Hospital, Oxford OX3 9DU

${ }^{\star}$ Correspondence to: A. Ali

REFEREED PAPER

Received 26.08.99; accepted 23.12.99

(C) British Dental Journal 2000; 188: 589-590

\section{In brief}

- Surgical emphysema and pneumomediastinum are the potentially life threatening complications from the use of the air rotor during exodontia.

- Potential microbial contaminants such as pseudomonas and legionella in dental compressed air lines may be passed into tissue spaces. air rotor during dental surgery should be abandoned.

showed extensive surgical emphysema. His chest radiograph showed an extensive surgical emphysema and pneumomediastinum as shown in Figure 1, and the posteroanterior neck radiograph showed air in the tissue planes as in Figure 2. The electrocardiogram was normal.

Management consisted of admission to hospital for an intravenous antibiotic
- We recommend that the use of an
Fig. 1 Chest pneumomediastinum radiograph showing regime of cefuroxime $750 \mathrm{mg}$ tds and metronidazole $500 \mathrm{mg}$ tds with continuous cardiac and respiratory monitoring. The chest pain and emphysema quickly resolved and he was discharged from the hospital after 3 days on an antibiotic regime of oral ciprofloxcin $500 \mathrm{mg}$ bd and clindamycin $150 \mathrm{mg}$ qds to cover staphloccocus, streptoccocal, anaerobic and possible pseudomonas infection. He developed a focal alveolitis at the extraction site, from which a small bony sequestrum was shed latter. His further recovery was unremarkable.

\section{Discussion}

Surgical emphysema is an uncommon complication of routine dental extraction. ${ }^{1}$ Mediastinal emphysema was first reported by Turnbull in 1900, and the most consistent feature in the aetiology of surgical emphysema related to dental practice is the use of compressed air powered instruments and this has been reported following restorative, ${ }^{2}$ endodontic ${ }^{3}$ and periodontal treatment, ${ }^{4}$ extractions as well as more extensive surgical procedures involving the temporomandibular joint, ${ }^{5}$ orthognathic surgery and facial fractures. ${ }^{6,7}$ It is postulated that air is forced into the subcutaneous and fascial tissue planes and into the mediastinum. Air-powered drills, which are unsuitable for use in oral surgery, are those which vent air forward into soft tissues, the air carrying an unsterile mixture of water and oil with it.

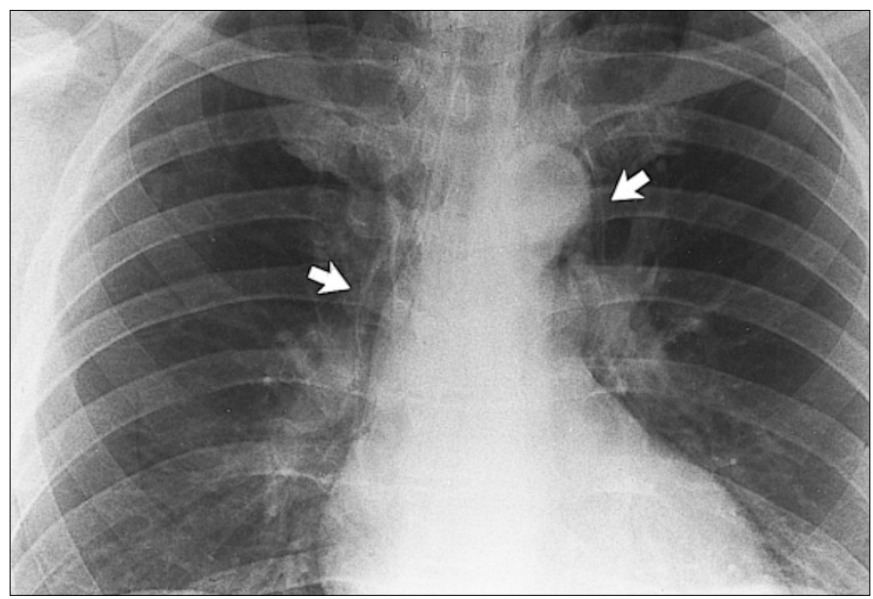


Subcutaneous emphysema has also been reported following the use of air syringes, hydrogen peroxide and patient activities such as sneezing, nose blowing and playing a brass instrument. ${ }^{8}$

The differential diagnosis of a patient presenting with facial and neck swelling, and surgical emphysema with chest pain includes; pneumothorax, oesophageal rupture, infection within fascial planes and subcutaneous emphysema with pneumomediastinum. The signs of mediastinal emphysema include subcutaneous emphysema, dull cardiac sounds, mediastinal crepitations with each heart beat and radiographic confirmation of air in the mediastinum. Distention of neck veins with facial engorgement may complicate massive air entrapment producing hypotension, hypercarbia and acidosis. This is known as malignant pneumomediastinum. Radiographical confirmation includes the characteristic parallel lines of radiolucency along the left cardiac border because of trapped air between the heart and left mediastinal pleura (Fig. 1). In the lateral film air is seen to be trapped retrosternally. Complications of cervical emphysema and pneumomediastinum would include infective mediastinitis, cardiac tamponade and airway obstruction. In addition it may be associated with simple and tension pneumothorax and pneumoperitoneum.

Treatment of pneumomedisatinum is symptomatic, monitoring cardiac activity, respiration and providing appropriate antibiotics and analgesia. Prevention of air embolus is the primary concern, using sedatives to decrease excessive respiratory effort, stool softener to limit valsalva manoeuvre, antitussive agents to suppress coughing, nasal decongestant and antihistamine to suppress nose blowing. Smoking must be prohibited.

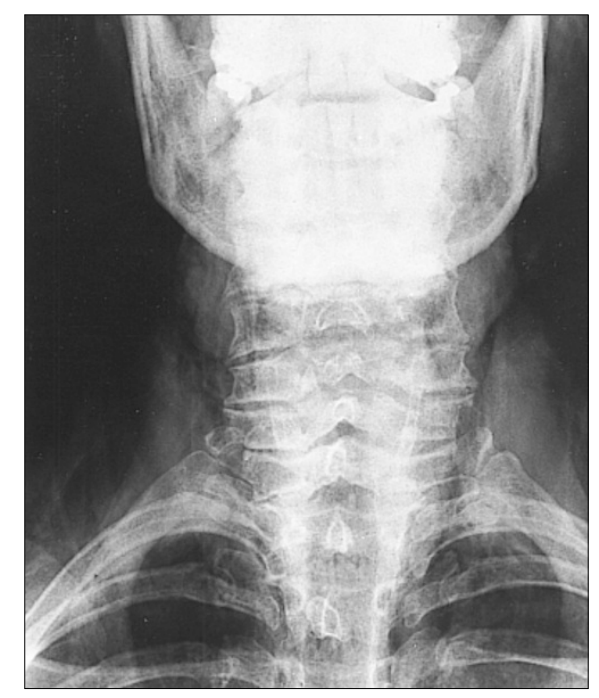

Fig. 2. Posteroanterior neck radiograph showing air in the tissue planes

Administration of $100 \%$ oxygen may be considered to increase the tendency of resorption of nitrogen by reducing its surrounding partial pressure. Serial chest radiographs are obtained to follow the progress of air resorption and to guide treatment. Secondary infective mediastinitis may occur through the site of mucosal or skin violation, depending on the mechanism of disruption and the patient's medical condition. Initial antibiotic treatment is with broad spectrum antibiotics to cover potential oral aerobes and anaerobes. Microbial contamination of dental compressed air lines has been extensively investigated with Pseudomona aeruginosa isolated from $15-24 \%$ of water lines. ${ }^{9}$ Legionella species has been isolated in dental waterlines, with the level of Legionella pneumophilia related to the presence of free living amoebae considered an important host for the growth of this organism. ${ }^{10}$ Free living amoebae can be isolated from the waterlines of $96-100 \%$ dental units while acanthamoebea can be recovered in $12 \%$ of water samples. ${ }^{11}$ The incidence of pneumomediastinum and cervical emphysema following dental extraction using an air rotor is rare, but possibly of serious consequence. We recommend that this practice should be abandoned.

1 Guest P G, Henderson S. Surgical emphysema of the mediastinum as a consequence of attempted extraction of third molar tooth using an air turbine drill. Br Dent J 1991; 171: 283-284.

2 Andsberg V, Axell T. Mediastinal emphysema as a complication of dental treatment. Odontol Res 1072; 23: 21-26.

3 Lloyed R E. Surgical emphysema: a complication in endodontics. Br Dent J 1975; 138: 393-394.

4 Snyder M D, Rosenberg E S. Subcutaneous emphysema during periodontal surgery: report of a case. J Periodontal 1977; 48: 790-791.

5 Chuong R, Boland T J, Piper M A. Pneumomediastinum and subcutaneous emphysema associated with

temporomandibular joint surgery. Oral Med Oral Surg Oral Pathol 1992; 74: 2-6.

6 Piecuch J F, West R A, Wash S. Spontaneous pneumomediastinum associated with orthognathic surgery. A case report. Oral Med Oral Surg Oral Pathol 1979; 48: 506-508.

7 Carmichael-F; Ward-Booth-R P, Banks-J M, Pneumomedistianum after facial trauma. . Oral Med Oral Surg Oral Pathol 1988; 66: 540-542.

8 Turnbull A. A remarkable coincidence in dental surgery. BMJ 1900: 1; 1131.

9 Barbeau J, Tanguay R, Faucher E et al. Multiparametric analysis of waterline contamination in dental units. Appl Environ Microbiol 1996b; 62: 3954-3959.

10 Wadowsky R M, Wilson T M, Kapp N J et al. Multiplication of legionella spp. in tap water containing hartmannella vemiformis. Appl Environ Microbiol 1991; 57: 1950-1955.

11 Michel R, Just H M, Acanthamoebae, Naegleria and other free living amoebae in cooling and rinsing water of dental units. Zentralbl Bakteriol Mikrobiol Hyg Ser B 1984; 179: 56-72. 